\title{
The Immature Stages of Protodasyapha (Protodasyapha) hirtuosa (Philippi) and their Comparison with the Immature Stages of other Pangoniini (Diptera: Tabanidae: Pangoniinae)
}

\author{
Christian R González
}

Instituto de Entomología, Universidad Metropolitana de Ciencias de la Educación, Casilla 147, Santiago, Chile

The terrestrial immature stages of the Chilean horse fly, Protodasyapha (Protodasyapha) hirtuosa (Philippi), are described. P.(P.) hirtuosa resembles Ectenopsis vulpecula Macquart and Caenoprosopon trichocera (Bigot) from Australia, and Esenbeckia delta Hine from North America, in both the larval and pupal stages. Some characters that are shared between these species are unique and provide evidence of their monophyletic origin. Larvae of P. hirtuosa were found 3-5 below of the soil surface and associated with larvae of Coleoptera, Lepidoptera and Diptera.

Key words: Tabanidae - Pangoniini - immature stages - Protodasyapha (P.) hirtuosa - Neotropical region - Chile

Tabanidae comprise a large and widely distributed family. Some species are important vectors of disease to man and domestic animals due to the hematophagous habits of the female (Krinsky 1976, Foil 1989). Other species can attack people working outdoors, reducing comfort and work efficiency and can attack cattle resulting in a decline in weight gain and lower milk production (Perich et al. 1986). Some species, however, are not haematophagous.

Very little is known about the immature stages of Tabanidae in the Neotropical region. Of 1,172 species catalogued by Fairchild and Burger (1994) the immatures of about 50 species are adequately described and studied. Coscarón $(1968,1991)$ described the immature stages of some species of Dasybasis Macquart from Chile and Argentina. Goodwin and Murdoch (1974) described the larvae and pupae of 22 species, particularly from Central America. Coscarón and Philip (1967) described the larva and pupa of Dasybasis fairchildi Coscarón \& Philip. Coscarón and Led (1969) described the immature stages of Tabanus claripennis (Bigot). Coscarón and González (1989) described the preimaginal stages of Scaptia (Scaptia) lata (Guérin-Méneville), a terrestrial Scionini from southern South America. Recently, Coscarón et al. (1996) described the immature stages of Myiotabanus barrettoi Fairchild from northern Ar-

Work supported by Dirección Investigación Universidad Metropolitana, Projects GAF 96-03 and GAF 97-01. Fax: +56-2-239.2067. E-mail: cgonza@ discovery.umce.cl Received 10 October 1997

Accepted 31 March 1998 gentina. Studies of the immature stages are very important because they facilitate biological and life history investigations, particularly for species of economic importance. Knowledge of the immature stages of Pangoniini is particularly scanty. The immature stages of only 4 of 17 Pangoniini genera are known: Ectenopsis Macquart (English 1952) and Caenoprosopon Rondani (English 1961) from Australia, Esenbeckia Rondani (Burger 1977) from North America and Stonemyia Brennan from Japan (Yamaguchi 1974). Immature stages of Apatolestes cited by Burger (1977) probably was not that species but is likely to be Stenotabanus flavidus (Hine) (Burger, pers. comm.).

The tabanid genus Protodasyapha Enderlein is represented in southern South America, particularly in Chile and Argentina, by four species in two subgenera, Protodasyapha Enderlein and Curumyia Coscarón. Coscarón (1976) revised this genus and compared both subgenera. $P$. hirtuosa (Philippi) is known only from Chile.

The adults of $P$. hirtuosa are small to medium sized (9-11 mm), blackish, slender; antennae black with eight flagellomeres and without a consolidated basal flagellomere; scape of antenna stout with long hairs. Eye pilose, unbanded, holoptic in male. Front broad, divergent, pruinose; frontal index 0.8-0.9. Frontal callus black, rectangular; touching eyes. Subcallus bare. Clypeus and genae blackish. Maxillary palpi blackish and without pore of sensorial organ. Proboscis black, short and stout and longer than maxillary palpi. Body pilosity sparse. Wings smoky; R4 with short appendix. Leg blackish, hairy. Abdomen blackish; sternites and pleura grayish. 


\section{MATERIALS AND METHODS}

Specimens were found living in soil of the National Reserve of Río Clarillo, $50 \mathrm{~km}$ southeast of Santiago city, Cordillera Province, Chile, from September to December. This National Reserve has a mediterranean climate with seven months of dry conditions and five months with rains. Broad sclerophyll evergreen trees and shrubs dominate the vegetation. Eleven larvae were found $3-5 \mathrm{~cm}$ beneath the soil surface of a Lithraea forest, on a steep and humid hillside. They were collected with a hand trowel. Specimens were transported to the laboratory and kept in individual plastic boxes with a wet paper towel to maintain conditions like those of the natural habitat. In the laboratory P. hirtuosa larvae were fed living lepidopterous larvae of Ephestia and terrestrial crane fly larvae (Tipulidae).

Morphological studies were made with a stereoscopic microscope on living larvae which immobilized and relaxed in ice water. In addition, three larvae were killed by placing them in hot water at to $80^{\circ}-90^{\circ} \mathrm{C}$ and preserved, five larvae stored in $70 \%$ alcohol. For microscopic studies, structures (larval exuviae, head capsule and measurements of the anal segment) were mounted on slides in Canadian balsam. Preserved larvae were also examined to determine the pattern of pubescence and shape of the anal segment. The color of the integument and pattern of pupae were noted in living specimens. Morphological details of the larvae were studied with a compound microscope. Drawings were made with a camera lucida by the author.

The terminology of larvae and pupae follows of Teskey (1969) and Lane (1975). The specimens are deposited in the Instituto de Entomología, immature stages collection.

\section{RESULTS}

\section{Description of the immature stages of P.(P.) hirtuosa (Philippi)}

Mature larva: length 12-13.5 mm, creamy white. Body without trichomes; pseudopodia scarcely developed and concolorous with body coloration; body fully striated (Fig. 1). Body long and slender, broadest at level of thoracic segments 2 and 3 . Cephalic capsule light brown, $2.75 \mathrm{~mm}$ long; greatest width $0.48-0.51 \mathrm{~mm}$. Clypeus pale brown, pilose on the lower edge, long, slender and sharply pointed, terminating in a small upturned labrum (Fig. 2). Mandibles blackish brown, slender and blade-like, straight, ventral margin lacking serrations, length 0.60- $0.62 \mathrm{~mm}$ (Fig. 3). Antennae three segmented; basal and second segments long and slender, $0.275 \mathrm{~mm}$ and $0.15 \mathrm{~mm}$ long, respectively; third segment short, not bifid and less than half the length of the second, $0.035 \mathrm{~mm}$ (Fig. 4). Maxillary palpi slender and elongated; basal segment short and broad, $0.125 \mathrm{~mm}$ long; second segment long and tapering gradually to the short third segment, $0.219 \mathrm{~mm}$ and $0.045 \mathrm{~mm}$ long, respectively (Fig. 5). Cephalic brushes absent. Prothorax lighter than remaining segments, bearing fine pubescence laterally, dorsal striations separated by $0.045-0.057$ $\mathrm{mm}$. Meso and metathoracic segments with striations separated by $0.055-0.065 \mathrm{~mm}$ dorsally and 0.050-0.055 mm ventrally. Abdominal segments with 3 pseudopodia ventrally and 2 pseudopodia laterally; those of abdominal segments VI - VIII not well developed. Anal segment 1.05-1.10 mm long, hemispherical and without well developed pseudopodia (Fig. 6). Anal ridge with fine and scanty pubescence (Fig. 7). Respiratory siphon replaced by a stigmatal spine $0.60-0.62 \mathrm{~mm}$ long; the spine smoothly curved upward and retractible within the anal segment. Longitudinal striations present on anal segment, tracheal length 0.70- 0.75. Graber's organ not visible in living larvae.

Male pupa: maximum length $14 \mathrm{~mm}$, pale brown, darker near frontal tubercles and thoracic spiracles (Fig. 8). Frontal tubercles prominent and separated, raised $0.19-0.20 \mathrm{~mm}$, strongly sclerotized, smoothly curved forward and with sharply pointed apices. Antennal sheaths reaching epicranial suture, $0.59 \mathrm{~mm}$ long, $0.22 \mathrm{~mm}$ wide, annulated (Fig. 9). Callus tubercle robust, elevated and pointed, well sclerotized, length 2-2.1 mm, each bearing one long seta $0.67 \mathrm{~mm}$ long (Fig. 10); vertical setae $0.39 \mathrm{~mm}$ long; one pair of lateral orbital setae, 0.45 $\mathrm{mm}$ long; anterior orbital setae $0.44 \mathrm{~mm}$ long, posterior orbital setae $0.55 \mathrm{~mm}$ long; antennal ridge well sclerotized. Thoracic spiracles small, 0.12$0.13 \mathrm{~mm}$ long, shaped as in Fig. 11 and situated very close to epicranial suture; spiracular prominences not exceeding anterodorsal margin of thorax. Two pairs of basalalar setae present, $0.57 \mathrm{~mm}$ long and one pair of anterior mesonotal setae, 0.47 $\mathrm{mm}$ long; and one pair of posterior mesonotal setae $0.51 \mathrm{~mm}$ long. Two pairs of metanotal setae present, sublaterally $0.70-0.73 \mathrm{~mm}$ long, quite close together, one pair situated anterolaterally at the basal angle of the wing sheaths, $0.53 \mathrm{~mm}$ long. First abdominal segment with one pair of tergal setae $0.28 \mathrm{~mm}$ long and three pairs of pleural setae, 0.36-0.39 mm long. Abdominal fringe spines biseriate; spines of posterior series longer and thicker than spines of anterior series. Pleural spines longer than tergal and sternal spines on all segments. Abdominal segments II to VI with about 23-25 well developed spines on the posterior border, uniseriate and variable in size, but similar in shape (Fig. 12). Abdominal segment VII with 3540 spines, these spines longer than on other seg- 

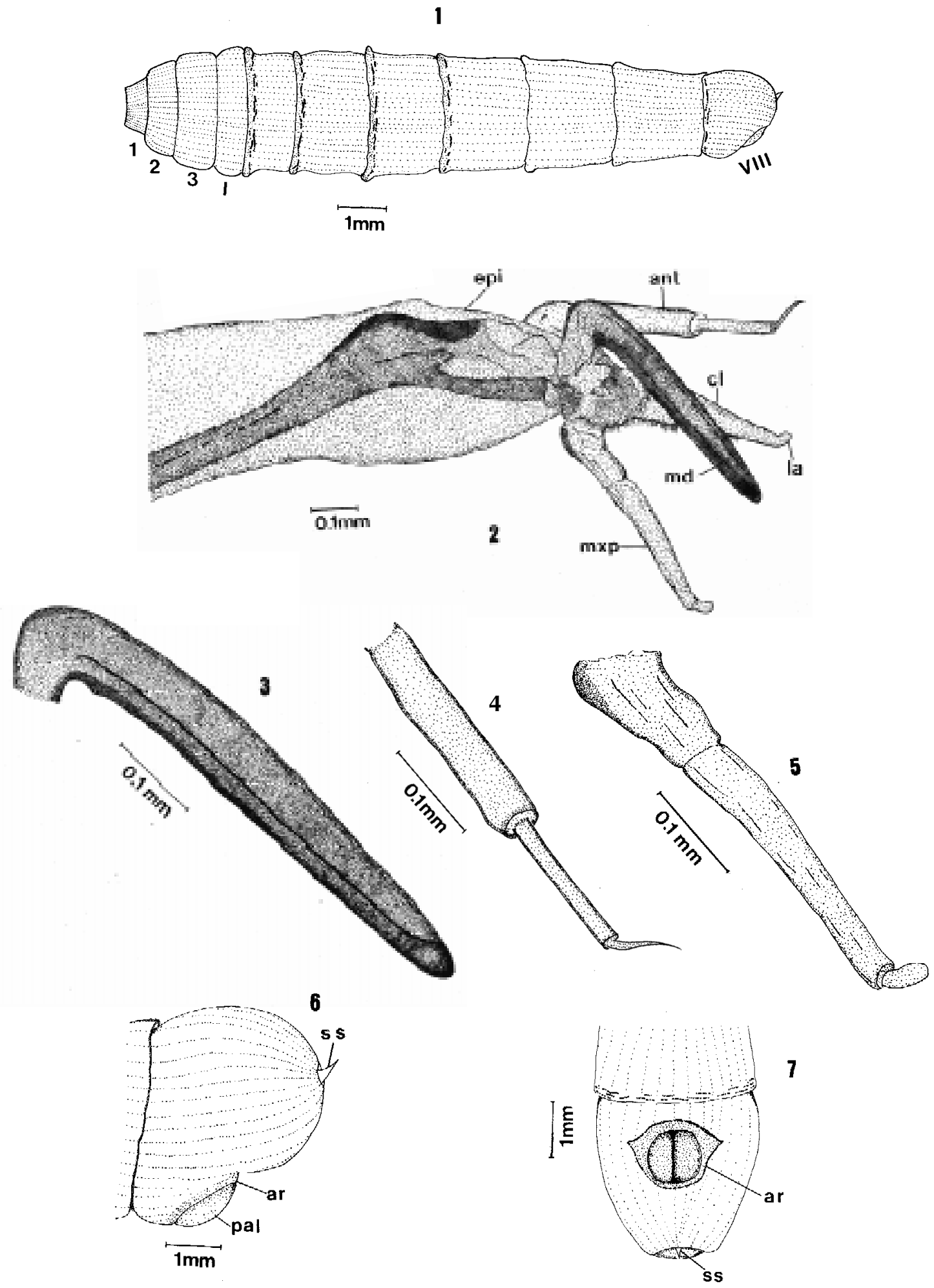

Protodasyapha (Protodasyapha) hirtuosa (Philippi), larva. Fig. 1: general aspect of mature larva in lateral view (1-3: thoracic segments, I-VIII: abdominal segments). Fig. 2: part of cephalic capsule showing the antennae, mandible and maxillary palpi (ant: antennae, cl: clypeus, epi: epicranium, la: labrum, md: mandible, mxp: maxillary palpi). Fig. 3: mandible. Fig. 4: antennae. Fig. 5: maxillary palpi. Fig. 6: posterior end of the larva in lateral view (ar: anal ridge, pal: posterior anal lobe, ss: stigmatal spine). Fig. 7: posterior end of the larva in ventral view. 

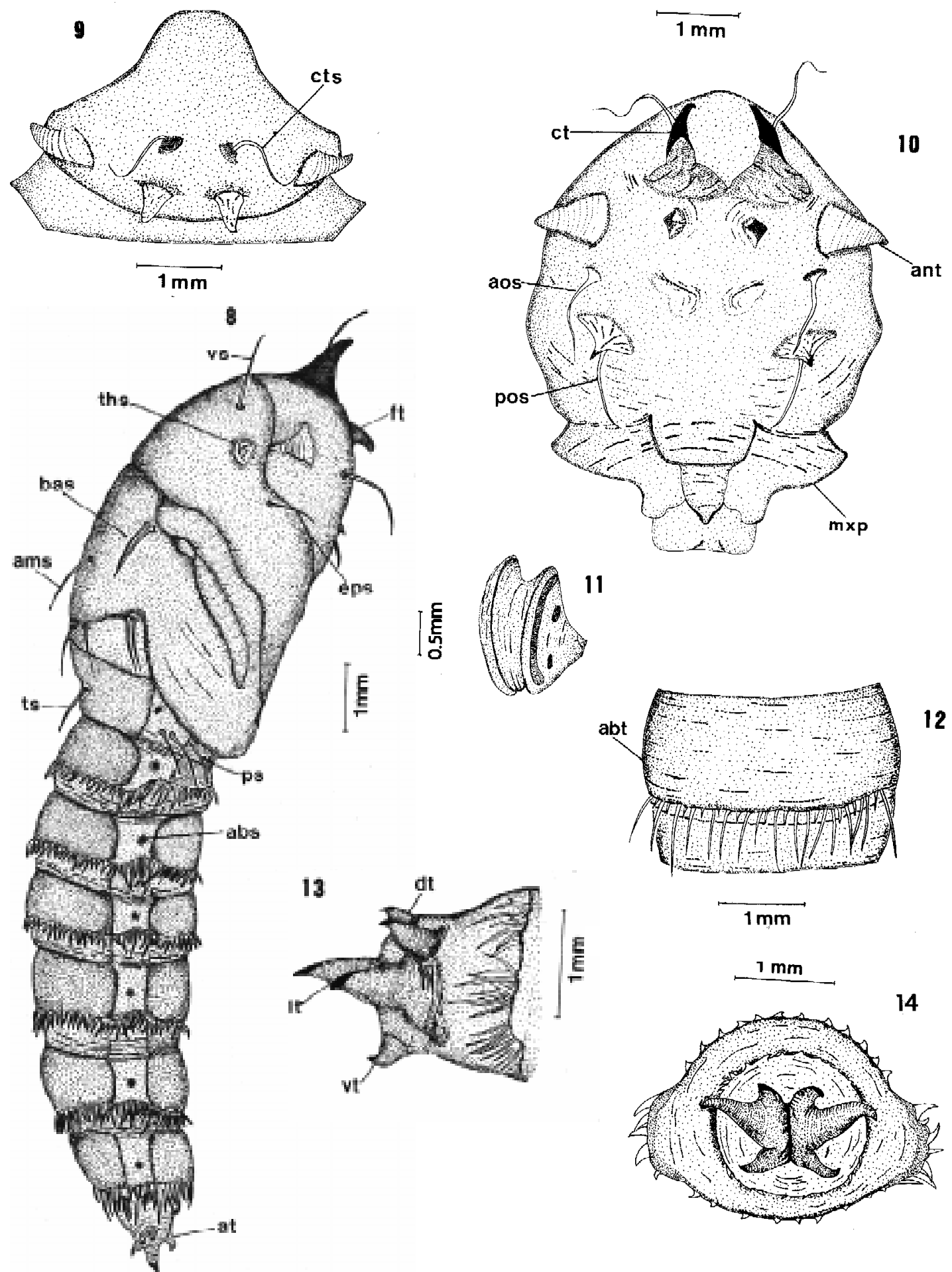

Protodasyapha (Protodasyapha) hirtuosa (Philippi), male pupa. Fig. 8: general aspect of pupa in lateral view (abs: abdominal spiracle, ams: anterior mesonotal setae, at: aster, bas: basalar setae, eps: epicranial suture, ft: frontal tubercles, ps: pleural setae, ts: tergal setae, ths: thoracic spiracle, vs: vertical setae). Fig. 9: frontal plate in anterior view (cts: callus tubercle setae). Fig. 10: frontal plate in ventral view (aos: anterior orbital setae, ant: antennal sheats, ct: callus tubercle, pos: posterior orbital setae, mxp: maxillary palpi). Fig. 11: thoracic spiracle in lateral view. Fig. 12: spines of posterior border of the abdominal tergite V (abt: abdominal tergite). Fig. 13: anal segment of the pupa in lateral view (dt: dorsal tubercle, lt: lateral tubercle, vt: ventral tubercle). Fig. 14: anal segment of the pupa in posterior view. 
ments, the longest $0.39-0.45 \mathrm{~mm}$. Preanal combs (lateral, dorsolateral and ventrolateral) form a more or less continuous line from dorsolateral to ventrolateral surface; preanal comb spines 0.34-0.39 $\mathrm{mm}$ long (Fig. 13). Aster, 1.25-1.30 mm long, with dorsal tubercles well developed; dorsal tubercles divergent, oriented dorsally, $0.43 \mathrm{~mm}$ long; lateral tubercles widely divergent, oriented posteriorly, 0.8 mm long; ventral tubercles divergent, oriented posteriorly, $0.29 \mathrm{~mm}$ long (Fig. 14).

Material examined: Chile, Prov. Cordillera, Reserva Nacional de Río Clarillo, Quebrada Los Almendros (800-950 m above sea level) 29.X.1992 P Estrada col.: 6 larvae (3 reared in the laboratory from a mature larvae to a pupa and only 2 male emerged: 15.XII.92 and 19.XII.92); 13.IX.1994 CR González col.: 2 larvae (all died) and 16.XII.1996 I. Mellado col.: 3 larvae (all died).

\section{COMPARISON WITH IMMATURE STAGES OF OTHER PANGONIINI}

The known immature stages of Pangoniini exhibit generalized characters: straight mandibles without cephalic brushes, body slightly wider in the metathorax and with a peculiar arrangement of pseudopodia in the larva, the callus tubercles elevated, arrangement of the three setae of meso and metathorax, and first abdominal tergite in the pupae. Although these larvae and pupae have some characters shared with other Pangoniinae, some characters are unique to the Pangoniini and provide evidence of their monophyletic origin (Teskey 1969).

The larvae and pupae of $P$. hirtuos $a$ are different from all other immature Tabanidae known from the Neotropical region. They resemble Pangoniini from Australia and North America but there are some differences. Thus, they share some characters unique to known Pangoniini: the straight mandibles, integument fully striated, pseudopodia well developed on no more than the first five abdominal segments in the larva, and the three dorsal setae of the mesothorax, metathorax and the first abdominal tergite of the pupa.

Larvae of Protodasyapha Enderlein differ from larvae of Ectenopsis Macquart in following characters: an anal segment with prominent terminal processes are absent and the basal segment of the antennae is shorter. However, both species have a stigmatal spine. The pupa of Protodasyapha has the following differences from Ectenopsis: tubercles of the aster shorter, and antennal ridge less prominent. Larvae of Protodasyapha have the following differences from Caenoprosopon Rondani: abdominal pseudopodia less prominent, stigmatal spine present, the third segment of the antennae not bifid, and the basal segment of antennae is long and slender at the base, labrum with small upturned apex, the anal segment without four pairs of long, slender setae and two short hairs near of spiracles. The pupa of Protodasyapha have the following differences from Caenoprosopon: the shape of the aster, only one medial mesonotal setae (one pair in Caenoprosopon), antennal sheaths reaching the epicraneal suture, and callus tubercle bearing one long setae. The larvae of Protodasyapha has the following differences from Esenbeckia delta Hine: labrum with small upturned apex, anal abdominal segment with a stigmatal spine, and the third antennal segment not bifid.

\section{DISCUSSION}

The immature stages of $P$. hirtuosa resemble E. vulpecula Macquart and C. trichocera (Bigot) from Australia and E. delta Hine from North America in many morphological characters and living in a terrestrial habitat. It is likely that the stem-form of the Pangoniinae (Pangoniini and Scionini) was terrestrial, while the general trend of the other subfamilies of Tabanidae has been toward semiaquatic and aquatic habits. The semiaquatic and aquatic forms (Diachlorini and Tabanini for example) are the most derived since the larvae of Diptera - Brachycera are primitively wood or humus feeding (terrestrial). In other families of Diptera, Psychodidae for example, larvae of the most plesiomorphic subfamilies are likewise terrestrial (Duckhouse 1994).

\section{ACKNOWLEDGEMENTS}

To Dr S Coscarón (Universidad Nacional de La Plata, Argentina) and Dr JF Burger (University of New Hampshire, USA) for reviewing the manuscript and the latter for help in editing the English version.

\section{REFERENCES}

Burger JF 1977. The biosystematics of immature Arizona Tabanidae (Diptera). Trans Amer Ent Soc 103: 145-258.

Coscarón S 1968. Datos sobre estados preimaginales de Tábanos neotropicales (Diptera: Tabanidae). Rev Soc Entomol Argentina 31: 19-22.

Coscarón S 1976. Contribución al conocimiento de los Tabanidae Neotropicales II. Los Pangoniini del Sur de Sud América y datos sobre la Tribu Scepsidini. Rev Mus La Plata, NS XII, Sec Zool, 114: 75-116.

Coscarón S 1991. Los estados inmaduros de 7 especies neotropicales del género Dasybasis Macquart (Tabanidae, Diptera, Insecta). Acta Ent Chilena 16: 7-24.

Coscarón S, Coscarón-Arias LC, Mancebo OA 1996. The immature stages of Myiotabanus barrettoi Fairchild (Tabanidae-Diptera-Insecta). Mem Inst Oswaldo Cruz 91: 21-26.

Coscarón S, Led JE 1969. Contribución al conocimiento de Tabanus claripennis (Bigot) con especial referencia a la morfología y biología de sus estadios 
preimaginales. Analecta Veterinaria 1: 13-15.

Coscarón S, Philip CB 1967. Notas sobre biología y morfología de estadios preimaginales y descripción del macho de Dasybasis fairchildi Coscarón \& Philip. Rev Soc Entomol Arg 29: 43-51.

Coscarón S, González CR 1989. Los estados preimaginales del "colihuacho" Scaptia (Scaptia) lata (Guérin-Méneville) (Tabanidae: Diptera). Acta Ent Chilena 15: 249-256.

Duckhouse DA 1994. The final-stage larvae of Brunettia (Diptera: Psychodidae: Psychodinae) and their evolutionary significance. Invertebr Taxon 9: 83-105.

English KMI 1952. Notes on the morphology and biology of Ectenopsis vulpecula Wied. var. angusta Macq. (Diptera, Tabanidae, Pangoniinae). Proc Linn Soc NSW 77: 270-274.

English KMI 1961. Notes on the morphology and biology of Caenoprosopon trichocerus (Bigot) (Diptera, Tabanidae, Pangoniinae). Proc Linn Soc NSW 86: 169-176.

Fairchild GB, Burger JF 1994. A Catalog of the Tabanidae (Diptera) of the Americas South of the United
States. Mem Am Entom Inst 55: 249.

Foil L 1989. Tabanids as vectors of disease agents. Parasitol Today 5: 88-96.

Goodwin JT, Murdoch WP 1974. A study of some immature Neotropical Tabanidae (Diptera). Ann Entomol Soc Am 67: 85-133.

Krinsky WL 1976. Animal disease agents transmitted by horse flies and deer flies (Diptera: Tabanidae). $J$ Med Entomol 13: 225-275.

Lane RS 1975. Immatures of some Tabanidae (Diptera) from Mendocino County, Calif. Ann Entomol Soc Amer 68: 803-819.

Perich MJ, Wright RE, Lusky KS 1986. Impact of horse flies (Diptera: Tabanidae) on beef cattle. J Econ Entomol 79: 128-131.

Teskey HJ 1969. Larvae and pupae of some eastern North American Tabanidae (Diptera). Mem Entomol Soc Canada 63: 1-147.

Yamaguchi H 1974. Ecological studies on tabanid larvae (1). On the morphological external characters by observation and rearing (in Japanese). Shinano Kyoiku 9: 1-19. 